\title{
Drivers and barriers to adopting relational contracting practices in public projects: Comparative study of Beijing and Sydney
}

\author{
Florence Yean Yng Ling, Shi Ying Ong, Yongjian Ke, ShouQing Wang, Patrick Zou
}

\begin{abstract}
When contracting parties adopt relational contracting (RC) as opposed to formal contracting stance, the construction project may achieve good outcomes. However, public projects usually face more constraints in adopting RC, as close relationships may lead to allegations of corruption. The aim of this study is to undertake a comparative analysis of drivers and barriers to adopting RC practices in public construction projects in two different markets viz. a centrally planned economy and a free market economy by investigating practices in Beijing and Sydney. The survey research design was adopted and data of public construction projects in Beijing and Sydney were collected using a structured questionnaire. The results revealed that relationship quality and level of harmony among contracting parties are significantly good in both cities. In Sydney, the level of inter-personal relations between contractors and consultants is significantly higher than in Beijing. It was found that the same 18 factors drive contracting parties in Beijing and Sydney to adopt RC practices, and in 6 instances, these are significantly greater drivers in Sydney. The barriers to adopting RC practices are totally dissimilar in both cities. Contracting parties in Beijing could not adopt more RC practices because of a lack of training in relational arrangement and public clients lack initiative in adopting RC practices. The conservative industry culture that encourages preservation of the status quo is also prevalent in Beijing. In Sydney, the only significant barrier is public sector accountability concerns. To cultivate readiness to embrace RC practices, it is suggested that industry professionals and the government adopt recommendations highlighted in this study according to the type of market structure.
\end{abstract}

Keywords: Project outcome; Performance; Relational contracting; China; Australia

\section{Introduction}

In the construction industry, the practice of adopting adversarial contracting approaches and the pursuit of individual company gain have produced a less efficient industry with criticisms relating to low productivity and innovation (Egan, 1998; Kumaraswamy et al., 2010). The poor delivery of clients' objectives has been traced to the incompetence of stakeholders to engage cooperatively (Colledge, 2005). Cooperative engagements suggest that parties need to develop close relationships.

Copyright: International Journal of Project Management (C) 2014 Florence Yean Yng Ling, Shi Ying Ong, Yongjian Ke, ShouQing Wang, Patrick Zou. This is an Open Access article distributed under the terms of the Creative Commons Attribution 4.0 Unported (CC BY 4.0) License

(https://creativecommons.org/licenses/by/4.0/), allowing third parties to copy and redistribute the material in any medium or format and to remix, transform, and build upon the material for any purpose, even commercially, provided the original work is properly cited and states its license.

Citation: Ling, F. Y. Y., Ong, S. Y., Ke, Y., Wang, S. Q., \& Zou, P. (2014). Drivers and barriers to adopting relational contracting practices in public projects: Comparative study of Beijing and Sydney. International Journal of Project Management, 32(2), 275-285. doi:

10.1016/j.ijproman.2013.04.008

Corresponding author: Florence Yean Yng Ling; Email - bdglyy@nus.edu.sg 
Relationships between multiple project team members can be based on formal contractual liaisons, relational links or a combination of each. In a formal contract, parties usually act in an atomized manner, looking out for their own personal interests (Williamson, 1975). On the other hand, relational contracting (RC) embraces and underpins different approaches that establish working relationships between the parties aimed at win-win situations for all (Sanders and Moore, 1992). RC allows mutual future planning and considers contracts to be relationships among the parties, in the process of projecting the exchange into the future (Macneil, 1974). RC practices such as collaborative working arrangements are expected to be adoptable in private sector projects.

On the one hand, contracting parties in public sector projects need to maintain arm's length relationship with each other to avoid allegations of corruption. Moreover, public projects are usually procured through a competitive bidding process and thus public clients have lesser rights to offer future relationships to contractors. On the other hand, greater adoption of RC practices is beneficial as it leads to better project outcomes (Ling and Tran, 2012). Research is therefore needed to find ways to increase the usage of RC, and remove the obstacles to the adoption of RC practices in public projects.

The aim of this study is to undertake a comparative analysis of drivers and barriers to adopting RC practices in public construction projects in a centrally planned market and a free market economy represented by Beijing and Sydney respectively. The specific objectives are to: identify relationship quality among contracting parties; investigate if there is significant difference in relationship quality in both markets; identify significant differences in drivers and barriers to adopting RC practices in the two markets; and offer recommendations on how to increase adoption of RC practices in the two different markets.

International architectural, engineering or construction (A/E/C) firms would be interested in China (represented by Beijing in this study) because it is the world's second largest economy and its construction industry has achieved healthy growth and development in the recent years (Tai et al., 2009), making it a likely market destination for international $A / E / C$ firms. Non-Chinese international $\mathrm{A} / \mathrm{E} / \mathrm{C}$ firms with the intention to enter China's construction market are likely to be familiar with an open market economy. To inform them of how different it would be to operate in China, Australia (represented by Sydney) was used to contrast the findings from China because it has a free market economy.

As both China and Australia are large countries in terms of geographical spread, Beijing and Sydney were selected for in depth study. Beijing was chosen because it is China's capital and is the epitome of a centrally planned economy. Sydney was chosen to represent a free Western market economy.

The comparative study between Beijing and Sydney may inform A/E/C firms of how different types of markets shape the motivating and impeding factors that influence RC adoption in public projects. With knowledge of the specific drivers and barriers in different markets, $\mathrm{A} / \mathrm{E} / \mathrm{C}$ firms may be able to implement RC practices successfully in the respective markets.

\section{Definitions}

Yeung et al. (2012) differentiated between relational contracting (RC) and relational contract. RC is a philosophy or a set of principles that are adopted in a contract. RC is defined as the working relationships among the parties who do not often follow the legal mechanism offered by the written contracts, and instead govern the transactions themselves within mutually acceptable social guidelines (Macaulay, 1963). RC focuses on trust and partnership (Colledge, 2005). Rahman and 
Kumaraswamy $(2004,2005)$ found that RC provides the means to sustain ongoing relations in long and complex contracts by adjustment processes of a more thoroughly transaction-specific, continuous and administrative kind. Some examples of RC practices include having flexibility when situations change, compromising on unclear issues, sharing project information and solving problems jointly.

Relational contract is a contract containing elements of RC (Yeung et al., 2012). The types of relational contracts include project partnering (CII, 1991), strategic partnering (Bennett and Jayes, 1998), project and strategic alliances (Walker et al., 2002), public private partnership and joint ventures (Palaneeswaran et al., 2003). It is a set of contracting principles that provides an alternative for people carrying out transactions to cooperate and implement specific measures in the contract especially in times of uncertainty and complexity (Macneil, 1974). A relational contract is a sub-set of RC practices.

This study focuses on the drivers and barriers to adopting RC practices in public projects in China and Australia, represented by Beijing and Sydney respectively.

\section{Market structures of China and Australia}

China maintains a centrally planned economy, also called authoritarian capitalism (McGregor, 2012) where the state directs and controls a large share of the country's economic output. The Chinese government usually controls and assigns construction works to nominated construction enterprises in its centrally planned economy (Liu and Low, 2007) through administrative orders (Zhang, 2003).

Australia operates a free market economy. Individual consumers and businesses act in their own rational interests while producers produce what consumers need and want (Bollen, 2007). Its government has a policy of laissez-faire, where there are not many laws and regulations to control businesses. The open market competition in Australia encourages economic benefits in its building and construction industry, which plays a significant role in the economic prosperity of the country (Nitschke, 2010).

The economies of China and Australia present two poles, and hence a comparative study of the drivers and barriers to adopting RC practises could inform $\mathrm{A} / \mathrm{E} / \mathrm{C}$ firms of unique challenges when operating in different markets.

\section{Drivers for adopting RC practices}

The motivating factors that may lead to the adoption of RC practices were identified through literature review. They are classified into 5 constructs and are reviewed below.

\subsection{Better cost outcome}

Studies have shown that desiring better cost outcome drives the adoption of RC. Better cost outcome involves the reduction of: total project cost; cost of changing partners; and risks. Reducing total project cost can be achieved by cooperating with partners to share development costs and technologies (Akintoye and Main, 2007). Better cost outcome is achieved when risk sharing between partners takes place (Black et al., 2000; Li et al., 2001; Ross, 2003). The shift to medium and longterm relationships between contracting parties reduces the costs of developing new relationships. With the aid of a relational contract such as partnering, smaller construction firms can combine resources thereby maximizing resource utilization (Black et al., 2000). 


\subsection{Better time outcome}

Studies have shown that desiring better time outcome drives the adoption of RC. Better time outcome entails the reduction of project delivery time and public client's administration burden. According to Lu and Yan (2007), one of the incentives of relational contract is the ability to exercise better time control through better scheduling, more timely decisions and reliable programming. Additionally, unnecessary administration procedures may be avoided in partnering contracts (Chan et al., 2003).

\subsection{Better quality}

Desiring better quality may drive parties to adopt RC practices. Contracting parties adopt RC to experience improvement in quality and reduction in engineering rework (Chan et al., 2003).

Improvement in design may drive parties to adopt RC (Black et al., 2000). In a partnered project, parties involved will take on joint responsibility to ensure a safe working environment, leading to a reduction in hazardous working conditions and accidents (Chan et al., 2003).

\subsection{Increased satisfaction}

Contracting parties may be driven to adopt RC practices because they desire increased satisfaction. Increased satisfaction comes about through a cooperative working environment which provides effective resolution of problems or conflicts and maintenance of harmony ( $\mathrm{Lu}$ and Yan, 2007).

Firms adopting relational contracts are better able to anticipate potential problems and subsequently develop an action plan focusing on methods as well as solutions (Chan et al., 2003). Ali et al. (2010) found that parties in relational contracts learn from one another to improve problem-solving skills.

Parties may adopt RC because they are driven to build closer relationships with each other. Longterm relationships that are formed with public clients benefit the clients' businesses and performance of other parties (Swan and Khalfan, 2007). Responding to public, social and end-users' needs may drive parties to adopt RC practices because of the importance of providing quality services to customers (end-users) (Lu and Yan, 2007).

\subsection{Increased competitiveness}

The need to increase competitiveness may drive contracting parties to adopt RC practices (Lummus et al., 1998). Black et al. (2000) stressed that organizations cannot survive in a market that is becoming increasingly competitive without the support of their suppliers.

Relational contract in the form of strategic partnering increases organizational competency because it can be used to obtain and sustain a competitive advantage in the marketplace (Lu and Yan, 2007). Humphreys et al. (2003) found that strategic partnering allows several firms to work together on a long-term basis to undertake more than one project. Chan et al. (2003) concluded that collaborating provides the opportunity for all parties to achieve continuous improvement. Firms may also be driven to adopt RC practices to enhance their reputation (Jefferies et al., 2006). 


\section{Barriers to adopting RC practices}

The barriers to adopting RC practices are reviewed and classified into 5 constructs. These are discussed below.

\subsection{Lack of experience/knowledge in RC}

The lack of experience or knowledge in RC can impede the adoption of RC practices. Kumaraswamy et al. (2005) found that clients' lack of knowledge of relational approaches significantly deters the implementation of RC and the formation of a project-based integrated team. They argued that commitment from clients is imperative as they can more effectively drive the team building process as the project sponsor.

$\mathrm{Ng}$ et al. (2002) found that the lack of training and guidance in RC affected the attainment of project goals. Moreover, when parties have past negative experience of relational arrangement, it is difficult for them to adopt RC practices again (Glagola and Sheedy, 2002). Lastly, the lack of experience in relational arrangement poses a barrier to implementing RC due to a lack of understanding on how it works (Glagola and Sheedy, 2002).

\subsection{Misalignment among project participants}

A misalignment among project participants may impede the adoption of RC. Eriksson et al. (2008) reported that not all organizations have the will and ability to cooperate with other parties and their unenthusiastic participation is a common barrier to adopting relational approaches.

Akintoye et al. (2000) found that a lack of senior management support contributes to the failure of collaboration in construction projects. Lack of top management support may discourage individual decision makers from seeking new and more effective RC approaches (Eriksson et al., 2008). Furthermore, the lack of client's initiative in implementing RC practices dissuades other parties from adopting it (Rahman and Kumaraswamy, 2008).

The lack of common goals among contracting parties may be a barrier to implementing RC (Drexler and Larson, 2000). Packham et al. (2003) found that many problems arise because of different definitions of project goals. Drexler and Larson (2000) also pointed out that it is necessary to recognize that parties should work toward the same goals and need each other to achieve them.

\subsection{Adversarial environment}

The antagonistic culture and incompatible personalities between parties (Kumaraswamy et al., 2005) engender adversarial environment which impedes the adoption of RC. Contracting parties are used to working in opposition to each other to achieve their own objectives (Eriksson et al., 2008). The adversarial "win-lose" attitude exists due to a lack of trust among contracting parties (Ng et al., 2002).

Another barrier to RC adoption is the presence of opportunistic behaviors due to commercial pressures, absence of risk-reward plans and cultural clash at individual levels (Ke et al., 2011). The persisting adversarial setting deters contracting parties from adopting RC and instead may cause them to behave opportunistically (Rahman and Kumaraswamy, 2008). 
Incompatible culture at organizational and inter-personal levels may deter parties from adopting RC practices. Incompatible organizational cultures among contracting parties arise due to short-term focus on single projects (Eriksson et al., 2009). Inter-personal cultural clash may take place among project team members because they are of different nationalities (Hofstede, 2012).

\subsection{Cost and time to conduct RC}

The additional cost and time needed to conduct RC may impede its adoption. A substantial amount of cost may be needed to establish and maintain relational approaches (Ross, 2003). Cost may be incurred in cultural management which includes activities such as coaching and workshops (Ross, 2003). Bresnen and Marshall (2000) found that organizations need to spend additional cost to change their systems to facilitate open communication and information sharing between partner organizations.

To have successful relational contracts, a considerable amount of time is needed to find the right partners and develop the partnership (Cook and Hancher, 1990). Time is required to set up partnering charters and dispute resolution mechanisms, conduct team bonding exercises and workshops (Bresnen and Marshall, 2000).

\subsection{Uniqueness of public projects}

The uniqueness of public projects may be a barrier to adopting RC. Palaneeswaran and Kumaraswamy (2000) observed that clients, especially in the public sector, showed great reluctance to adopt changes and innovations as beliefs such as "there is no need to change current approaches/practices that are good enough" or a "not invented here” syndrome, do exist. Conservatism and inflexibility are barriers to RC since they hamper team work (Ng et al., 2002).

Parties adopting RC may project their current exchange into the future (Macneil, 1974). However, contracting parties have misgivings about future relationships because fresh tenders need to be called for each new public project (Drexler and Larson, 2000). The need to call fresh tenders is because the public sector needs to maintain transparency to avoid allegations of corruption, and it needs to be accountable to tax payers (Ke et al., 2013). The need for transparency and accountability leads to the enactment of stringent rules, regulations and laws.

\section{Gap in knowledge}

The literature review revealed the drivers and barriers to adopting RC practices in general without distinguishing between: public and private construction projects; and planned and free market economies. Public sector clients are usually restrained from offering future relationship incentives because of the need to go through competitive bidding process in the procurement of contractors and consultants' services. Furthermore, the use of taxpayers' money in public projects makes it politically expedient to award contracts to the lowest bidder. In a centrally planned economy, the government dictates or controls the project implementers, while in a free economy, the most efficient players are appointed to develop public projects.

The gap in knowledge is that it is not known if the drivers and barriers apply equally to public sector construction projects in a centrally planned economy and an open market economy. This study aimed to fill the knowledge gap by exploring and comparing the drivers and barriers to adopting RC practices in public projects in a centrally planned economy and an open market economy. 


\section{Research method}

\subsection{Research design}

A large research project was undertaken to investigate the drivers and barriers, and RC practices adopted in public construction projects in Beijing, Hong Kong, Singapore and Sydney. Using the survey research design, questionnaire surveys were conducted between June and November 2011 in these cities. The respondents were requested to provide data of a completed public sector project that they had been previously involved in. This paper reports on a part of the study, focusing on relationship quality among contracting parties and the driving and impeding factors for adopting RC practices in Beijing and Sydney.

Data were collected using a specially designed structured questionnaire. Section A requested information of a completed public sector construction project. Section B requested respondents to rate the relationship quality among contracting parties, on a 5-point scale, where: 1 = very bad; $3=$ neutral; and 5 = very good. Sections $C$ and $\mathrm{D}$ requested respondents to rate the extent to which they agreed with the drivers and barriers to adopt RC in the public project respectively. A 5-point scale was used where: 1 = strongly disagree; 3 = neither agree nor disagree; and $5=$ strongly agree. Section E investigated the RC practices adopted, but the results are reported elsewhere. A final section requested for the demographic characteristics of respondents and their companies. For the fieldwork in Beijing, the questionnaire was translated into Chinese.

Content validity was addressed during the questionnaire development stage by an in-depth literature review and a pilot test of the questionnaire with 9 industry practitioners.

The population comprised public sector construction projects in China and Australia. The total gross output value of state-owned construction for China in 2011 was RMB 2.078 trillion ( $\approx$ US\$ 335 billion) (National Bureau of Statistics China, 2012). The value of public sector construction work done in 2010-2011 in Australia was A \$48 billion ( $\approx$ US\$ 50 billion) (Australian Bureau of Statistics, 2012). The sampling frame is projects in Beijing and Sydney. Ideally, public officers should be approached to fill up the information of completed public project that were under their charge. This was not done because the response rate would be dismal. A research decision was made to approach multiple parties (public officials, contractors and consultants) who had been involved in public construction projects in these cities to provide information of completed public projects. To avoid repetitions in the data set, upon receiving a completed set of questionnaire, the characteristics of the project (section A) were checked to confirm that different respondents did not provide information of the same project.

The names and contact details of public officials were obtained from government directories. As the number of people in this group was not overwhelming, questionnaires were sent to all identified relevant public officials. The consultants and contractors were identified from their respective professional and trade institutions. Random sampling was used to select them. As this group may contain those who have not handled public projects, the questionnaire clearly stated that only those who had completed public projects should fill it up.

\subsection{Data analysis methodology}

There are many debates about whether Likert-scale data can be subjected to parametric statistical tests. Previous studies have found that the results from parametric tests with ordinal data are reasonably reliable (e.g., Carifio and Perla, 2008; Norman, 2011; Winter and Dodou, 2010). 
Compared to parametric methods, Winn and Johnson (1978:358) considered nonparametric methods are only "better than doing no statistical analysis at all". Armstrong (1980:62) stated that the opposition to the use of parametric statistics with ordinal data is "not sound theoretically, not necessary empirically and can have negative consequences if needlessly followed". Zumbo and Zimmerman (1993:390) stated that "there is no need to replace parametric statistical tests by nonparametric methods when the scale of measurement is ordinal and not interval”, and Norman (2011) proposed that the controversy can cease. This study therefore conducted parametric statistical tests such as One-sample T-test and Independent Sample T-test using the Statistical Package for Social Sciences (SPSS) software. The significance level for the tests was set at 0.05.

One-Sample T-test was conducted to find out the strength of relationship quality and identify significant drivers and barriers in Beijing and Sydney separately. The test value was set at 3 , which is the mean of a 5-point Likert scale. When $\mathrm{p}<0.05$ and the T-value are positive, it is concluded that there is significantly good relationship quality among contracting parties or there is significant agreement that a factor drives or impedes the adoption of RC practices in public projects.

The Independent Sample T-Test is used to determine whether there is a significant difference in the means of two independent samples. It was applied to compare whether there are significant differences in relationship quality, drivers and barriers between Beijing and Sydney samples. If $\mathrm{p}<$ 0.05, it indicates that respondents in Beijing and Sydney have rated significantly differently.

\section{Characteristics of the sample}

Questionnaires were sent to 259 and 322 samples in Beijing and Sydney respectively. 59 and 30 valid questionnaires were returned in Beijing and Sydney representing response rates of $22.8 \%$ and 9.3\% respectively. The response rate for Beijing is adequate but low for Sydney. Although the response rates are relatively low, statistical analysis could still be performed because in accordance with the generally accepted rule, central limit theorem holds true when the sample size is no less than 30 (Ott and Longnecker, 2001).

Cronbach's alpha reliability test was conducted to examine internal reliability of the data sets. The Cronbach's alpha values were 0.868 and 0.864 for drivers and barriers respectively for the Beijing data set. In the Sydney data set, the Cronbach's alpha values of drivers and barriers were 0.891 and 0.966 respectively. As these values are greater than 0.7, it suggests that the data are reliable and further statistical analyses may be conducted (Nunnally, 1978).

The characteristics of the respondents are given in Table 1. Beijing and Sydney respondents have an average of 11 and 24 years of experience respectively. The respondents' firms engaged an average of 19,934 and 7037 employees in Beijing and Sydney respectively. The respondents represent various types of organizations with the majority being construction firms. 
Table 1

Background of respondents.

\begin{tabular}{|c|c|c|c|c|c|}
\hline \multirow[t]{2}{*}{ Characteristic } & & \multicolumn{2}{|c|}{ Beijing } & \multicolumn{2}{|c|}{ Sydney } \\
\hline & & No. & $\%$ & No. & $\%$ \\
\hline \multirow{7}{*}{$\begin{array}{l}\text { Experience in } \\
\text { construction industry }\end{array}$} & $<5$ years & 8 & 13.8 & 6 & 20.7 \\
\hline & $5-9$ years & 14 & 24.1 & 1 & 3.4 \\
\hline & $10-14$ years & 22 & 37.9 & 1 & 3.4 \\
\hline & $\geq 15$ years & 14 & 24.1 & 21 & 72.4 \\
\hline & Average & 11 & & 24 & \\
\hline & Min & 2 & & 2 & \\
\hline & Max & 30 & & 45 & \\
\hline \multirow[t]{6}{*}{ Organization type } & Government & 10 & 16.1 & 9 & 31.0 \\
\hline & Engineering firm & 1 & 1.6 & 2 & 6.9 \\
\hline & Architectural firm & 10 & 16.1 & 1 & 3.4 \\
\hline & $\begin{array}{l}\text { Quantity surveying } \\
\text { firm }\end{array}$ & 5 & 8.1 & 1 & 3.4 \\
\hline & Contractor & 32 & 51.6 & 16 & 55.2 \\
\hline & Others & 4 & 6.5 & 0 & 0.0 \\
\hline \multirow{3}{*}{$\begin{array}{l}\text { Ownership of } \\
\text { organization }\end{array}$} & Public & 30 & 51.7 & 16 & 55.2 \\
\hline & Private & 13 & 22.4 & 13 & 44.8 \\
\hline & Joint venture & 15 & 25.9 & 0 & 0.0 \\
\hline \multirow{6}{*}{$\begin{array}{l}\text { Size of total } \\
\text { workforce }\end{array}$} & $<100$ & 12 & 21.1 & 2 & 7.1 \\
\hline & $100-999$ & 23 & 40.4 & 7 & 25.0 \\
\hline & $\geq 1000$ & 22 & 38.6 & 19 & 67.9 \\
\hline & Average & \multicolumn{2}{|c|}{19,934} & \multicolumn{2}{|l|}{7037} \\
\hline & Min & \multicolumn{2}{|l|}{25} & \multicolumn{2}{|l|}{3} \\
\hline & Max & \multicolumn{2}{|c|}{160,000} & \multicolumn{2}{|c|}{100,000} \\
\hline
\end{tabular}

\section{Results and discussion}

\subsection{Relationship quality among contracting parties in Beijing and Sydney}

The first objective of this study was to evaluate the relationship quality among contracting parties. Table 2 shows that relationship quality among contracting parties is significantly good (positive Tvalues and $\mathrm{p}<0.05$ ) in all aspects (B1 to B7) in both cities. This indicates that in a centrally planned economy (Beijing) or an open market economy (Sydney): there is significant harmony during the project (B1); relationships among clients, consultants and contractors at the end of project are significantly good (B2 to B4); and the inter-personal relations among contracting parties are significantly good (B5 to B7). The implication is that regardless of the market structure, contracting parties adapt to get along with each other. The results support Smyth and Edkins' (2007) finding that the management of relationship is the responsibility of individuals for any one relationship.

The second objective was to investigate if there is significant difference in relationship quality in both cities. The results in Table 2 show that there is generally no significant difference in B1 to B6 type of relationship quality in Beijing and Shanghai. The only significant difference is item B7. The result shows significantly better inter-personal relations between contractors and consultants in Sydney than in Beijing. Contractors in China are often responsible for construction risks, costs and schedule while consultants take responsibility for the project quality. The demarcation of responsibilities may have caused tensions between contractors and consultants in China (Lu and Yan, 2007). In addition, as the size of Beijing's construction market is much larger than Sydney, contractors and consultants in Beijing may be less familiar with each other hence lower level of inter-personal relations between them. The result concurs with Martinsuo and Ahola's (2010) finding that repeated exchanges are required to develop routine working practices and better relationships. 
Table 2

Relationship quality in Beijing and Sydney.

\begin{tabular}{|c|c|c|c|c|c|c|c|c|c|}
\hline \multirow[t]{2}{*}{ Code } & & \multicolumn{3}{|c|}{ Beijing } & \multicolumn{3}{|c|}{ Sydney } & \multicolumn{2}{|c|}{$\begin{array}{l}\text { Equality of } \\
\text { means }\end{array}$} \\
\hline & & Mean & T-value & Sig & Mean & T-value & Sig & T-value & Sig \\
\hline B1 & Harmony during the project & 3.58 & 5.587 & 0.000 & 3.50 & 2.096 & 0.045 & 0.293 & 0.771 \\
\hline B2 & Relationship between client and contractor at the end of project & 3.66 & 5.738 & 0.000 & 3.93 & 4.731 & 0.000 & -1.307 & 0.195 \\
\hline B3 & Relationship between consultant and contractor at the end of project & 3.68 & 5.943 & 0.000 & 3.76 & 3.448 & 0.002 & -0.331 & 0.742 \\
\hline B4 & Relationship between client and consultant at the end of project & 3.65 & 5.240 & 0.000 & 3.70 & 3.427 & 0.002 & -0.225 & 0.822 \\
\hline B5 & Level of inter-personal relations between client and contractor & 3.48 & 4.130 & 0.000 & 3.87 & 5.066 & 0.000 & -1.897 & 0.061 \\
\hline B6 & Level of inter-personal relations between client and consultant & 3.50 & 4.625 & 0.000 & 3.80 & 4.738 & 0.000 & -1.559 & 0.123 \\
\hline B7 & Level of inter-personal relations between contractor and consultant & 3.33 & 3.364 & 0.001 & 3.73 & 4.253 & 0.000 & -2.219 & 0.029 \\
\hline
\end{tabular}

\subsection{Drivers of RC in Beijing and Sydney}

Identifying significant differences in drivers and barriers to adopting RC in Beijing and Sydney was the third objective of this study. Table 3 presents the significant differences in drivers between the 2 cities.

Table 3

Drivers of relational contracting in Beijing and Sydney.

\begin{tabular}{|c|c|c|c|c|c|c|c|c|c|c|}
\hline \multirow[t]{2}{*}{ Constructs } & \multirow[t]{2}{*}{ Code } & \multirow[t]{2}{*}{ Drivers } & \multicolumn{3}{|c|}{ Beijing } & \multicolumn{3}{|c|}{ Sydney } & \multicolumn{2}{|c|}{$\begin{array}{l}\text { Equality of } \\
\text { means }\end{array}$} \\
\hline & & & Mean & T-value & Sig & Mean & T-value & Sig & T-value & Sig \\
\hline \multirow[t]{4}{*}{ Better cost outcome } & $\mathrm{C} 1$ & Reduce total project cost & 3.97 & 8.163 & 0.000 & 3.96 & 6.854 & 0.000 & 0.009 & 0.993 \\
\hline & $\mathrm{C} 2$ & Reduce risks and/or mitigate their influence & 3.46 & 3.576 & 0.001 & 4.14 & 8.000 & 0.000 & 0.075 & 0.941 \\
\hline & $\mathrm{C} 3$ & Reduce the cost of changing partner in projects & 4.16 & 12.642 & 0.000 & 3.50 & 2.201 & 0.036 & -0.147 & 0.884 \\
\hline & $\mathrm{C} 16$ & Maximize resource utilization & 3.83 & 7.151 & 0.000 & 4.04 & 6.914 & 0.000 & -1.059 & 0.293 \\
\hline \multirow[t]{3}{*}{ Better time outcome } & $\mathrm{C} 4$ & Reduce time in delivering the project & 3.71 & 6.746 & 0.000 & 4.21 & 7.718 & 0.000 & -2.678 & 0.009 \\
\hline & $\mathrm{C} 5$ & Reduce public client's administration burden & 3.19 & 1.795 & 0.078 & 3.54 & 3.382 & 0.002 & -1.811 & 0.074 \\
\hline & C6 & Provide an integrated solution of efficiency improvement & 3.81 & 8.485 & 0.000 & 3.89 & 6.408 & 0.000 & -0.513 & 0.609 \\
\hline \multirow[t]{5}{*}{ Better quality } & $\mathrm{C} 7$ & Improve the quality of project & 3.74 & 6.997 & 0.000 & 4.32 & 9.674 & 0.000 & -3.228 & 0.002 \\
\hline & $\mathrm{C} 8$ & Improve the design & 3.55 & 5.123 & 0.000 & 4.41 & 11.498 & 0.000 & -4.787 & 0.000 \\
\hline & $\mathrm{C} 10$ & Achieve better safety performance & 3.81 & 7.508 & 0.000 & 4.14 & 8.000 & 0.000 & -1.833 & 0.070 \\
\hline & C9 & Respond to technology changes & 3.53 & 4.510 & 0.000 & 3.64 & 3.204 & 0.003 & -0.492 & 0.624 \\
\hline & $\mathrm{C} 11$ & Facilitate creative and innovative approaches & 3.47 & 3.928 & 0.000 & 3.96 & 6.437 & 0.000 & -2.495 & 0.015 \\
\hline \multirow[t]{5}{*}{ Increased satisfaction } & $\mathrm{C} 17$ & Respond to collaborative culture in the project & 3.74 & 8.004 & 0.000 & 3.96 & 6.437 & 0.000 & -1.353 & 0.180 \\
\hline & $\mathrm{C} 14$ & Reduce disputes during the project & 3.83 & 8.376 & 0.000 & 4.18 & 10.193 & 0.000 & -2.147 & 0.035 \\
\hline & $\mathrm{C} 15$ & Build up closer relationship with contracting parties & 3.60 & 5.984 & 0.000 & 4.25 & 9.442 & 0.000 & -3.847 & 0.000 \\
\hline & $\mathrm{C} 19$ & Achieve continuity with prior developments & 3.82 & 7.343 & 0.000 & 3.50 & 2.750 & 0.011 & 1.586 & 0.116 \\
\hline & $\mathrm{C} 21$ & Respond to public/social/end-users' needs & 3.63 & 5.853 & 0.000 & 3.68 & 3.968 & 0.000 & -0.277 & 0.782 \\
\hline \multirow[t]{4}{*}{ Increased competitiveness } & $\mathrm{C} 20$ & $\begin{array}{l}\text { Respond to competitors' actions (enhance } \\
\text { competitive position) }\end{array}$ & 3.95 & 7.844 & 0.000 & 3.36 & 1.842 & 0.077 & 2.693 & 0.009 \\
\hline & $\mathrm{C} 13$ & Improve your organization's competency & 3.95 & 8.748 & 0.000 & 4.11 & 6.392 & 0.000 & -0.807 & 0.422 \\
\hline & $\mathrm{C} 12$ & Enhance your organization's reputation in the industry & 4.15 & 10.450 & 0.000 & 4.18 & 6.600 & 0.000 & -0.129 & 0.898 \\
\hline & $\mathrm{C} 18$ & $\begin{array}{l}\text { Seize new market opportunities (e.g. pursuing future } \\
\text { relationships) }\end{array}$ & 4.03 & 9.658 & 0.000 & 3.39 & 1.890 & 0.070 & 2.743 & 0.009 \\
\hline
\end{tabular}

Table 3 shows that there is no significant difference in 14 of the factors that drive the adoption of RC practices in Beijing and Sydney. This indicates that in many instances, the drivers of RC are similar in both centrally planned economy (Beijing) and open market economy (Sydney). The discussion below focuses on significantly different drivers.

While contracting parties in both cities are driven to adopt RC practices in order to reduce the time needed to deliver projects (C4), those in Beijing are significantly less driven by this factor than those in Sydney. The Chinese government strongly emphasizes timely completion of public projects (Liu et al., 2010), and centrally approves construction projects above US\$30,000,000 (Wang et al., 2000). The strict schedule control by the government supplants informal means such as RC practices to reduce the time needed to deliver public projects. Contracting parties in Beijing may therefore rely less on RC practices to reduce the time needed to deliver projects because the project duration is, to a large extent, under by the government's formal control. 
Table 3 shows that reduction in public client's administration burden (C5) is a significant driver of $\mathrm{RC}$ adoption in Sydney but not in Beijing. This is consistent with Beijing's centrally controlled market structure where the government actively controls the market (Liu et al., 2010), sees this as its administrative duty, and hence contracting parties do not see reduction in public client's administration burden as a driver to adopt RC practices.

While contracting parties in both cities regard factors C7, C8 and C11 as significant drivers of RC, Table 3 shows that those in Beijing are significantly less driven than those in Sydney to adopt RC because of the need to improve design (C8) and project quality (C7), and facilitate creative and innovative approaches (C11). A/E/C firms in Sydney strive to offer better design, higher quality and innovative output because they are operating in Australia's competitive environment. Indeed, Australia's competitiveness is ranked 20th as compared to China's 29th out of 144 countries (World Economic Forum, 2012). Conversely, Chinese A/E/C firms are less innovative, as attested by the low contribution rate of science and technology in its construction industry (Lu et al., 2008). There is also reluctance to evaluate advanced technology for its applicability in improving quality performance of construction projects (Dong, 2009).

Project participants in both Beijing and Sydney are significantly driven to adopt RC practices because of the need to reduce disputes during the project (C14) and build up closer relationships with other contracting parties (C15). However, Table 3 shows that Australians are significantly more driven than the Chinese in these aspects. One possible explanation is that the Chinese have always emphasized on guanxi (relationship or connection) as a way of life (Gellerstam and Wiesner, 2010) and do not need structured RC practices to achieve this. China and Australia's individualism indices are 20 and 90 respectively (Hofstede, 2012) suggesting significantly higher collectivism in China. In the collectivistic Chinese culture, it is believed that building trust and maintaining good relationships with business counterparts will bring many long-term benefits. Australians who have significantly higher individualism may need to consciously adopt RC practices to engender a collaborative working environment (Luo, 2007).

While contracting parties in both cities are significantly driven to adopt RC practices because of the need to respond to competitors' actions (C20) and seize new market opportunities (C18), practitioners in Beijing are driven to a significantly larger extent than those in Sydney. This is consistent with China's A/E/C firms that look for new markets in order to become globally competitive (Liu and Low, 2007). In Australia however, A/E/C firms increase their competitiveness progressively through applied research and innovation (Hampson and Brandon, 2004), and less through RC practices.

\subsection{Barriers to adopting RC in Beijing and Sydney}

The results in Table 4 show that Beijing respondents face 6 significant barriers to adopting RC while Sydney has only 1 barrier. The dissimilarity of barriers shows the unique problems faced by a centrally planned economy (Beijing) and an open market economy (Sydney) when trying to adopt RC practices. The discussion below highlights significant differences and offers recommendations on how to increase adoption of RC practices, which is objective 4 of this study. 
Table 4

Barriers to relational contracting in Beijing and Sydney.

\begin{tabular}{|c|c|c|c|c|c|c|c|c|c|c|}
\hline \multirow[t]{2}{*}{ Constructs } & \multirow[t]{2}{*}{ Code } & \multirow[t]{2}{*}{ Barriers } & \multicolumn{3}{|c|}{ Beijing } & \multicolumn{3}{|c|}{ Sydney } & \multicolumn{2}{|c|}{$\begin{array}{l}\text { Equality of } \\
\text { means }\end{array}$} \\
\hline & & & Mean & T-value & Sig & Mean & T-value & Sig & T-value & Sig \\
\hline \multirow{4}{*}{$\begin{array}{l}\text { Lack of experience/ } \\
\text { knowledge in RC }\end{array}$} & D1 & Lack of knowledge of relational approaches & 2.96 & -0.252 & 0.802 & 3.04 & 0.176 & 0.862 & -0.290 & 0.773 \\
\hline & D3 & $\begin{array}{l}\text { Lack of training and guidance in the relational } \\
\text { arrangement }\end{array}$ & 3.34 & 2.475 & 0.017 & 3.31 & 1.443 & 0.161 & 0.130 & 0.897 \\
\hline & D5 & Past negative experience of relational arrangement & 2.79 & -1.668 & 0.102 & 2.73 & -1.193 & 0.244 & 0.241 & 0.811 \\
\hline & D6 & Lack of experience of relational arrangement & 3.08 & 0.468 & 0.642 & 3.00 & 0.000 & 1.000 & 0.264 & 0.792 \\
\hline \multirow{6}{*}{$\begin{array}{l}\text { Misalignment among } \\
\text { project participants }\end{array}$} & D9 & Unenthusiastic participation of contracting parties & 3.02 & 0.159 & 0.875 & 2.23 & -3.801 & 0.001 & 3.599 & 0.001 \\
\hline & D10 & Lack of top management support (each party) & 3.06 & 0.417 & 0.678 & 2.38 & -2.476 & 0.020 & 2.602 & 0.011 \\
\hline & D15 & $\begin{array}{l}\text { Lack of acceptance by contracting parties of relational } \\
\text { approaches as a long-term way of doing business }\end{array}$ & 3.00 & 0.000 & 1.000 & 2.77 & -1.140 & 0.265 & 0.919 & 0.361 \\
\hline & D11 & $\begin{array}{l}\text { Lack of client's initiatives in relational contracting } \\
\text { practice }\end{array}$ & 3.49 & 4.111 & 0.000 & 2.73 & -1.158 & 0.258 & 3.229 & 0.002 \\
\hline & D8 & Lack of empowerment in the client's representatives & 3.40 & 2.981 & 0.004 & 2.69 & -1.248 & 0.224 & 2.747 & 0.007 \\
\hline & D13 & Lack of common goals among contracting parties & 2.79 & -1.261 & 0.213 & 2.50 & -1.830 & 0.079 & 0.966 & 0.337 \\
\hline \multirow{4}{*}{$\begin{array}{l}\text { Adversarial } \\
\text { environment }\end{array}$} & D4 & Lack of trust among all contracting parties & 3.13 & 0.943 & 0.350 & 2.77 & -0.881 & 0.387 & 1.221 & 0.229 \\
\hline & D16 & Inter-personal/cultural clash (individual level) & 2.82 & -1.219 & 0.228 & 2.73 & -1.070 & 0.295 & 0.343 & 0.733 \\
\hline & D19 & $\begin{array}{l}\text { Concerns about opportunistic behavior of other } \\
\text { contracting parties }\end{array}$ & 3.12 & 0.973 & 0.335 & 3.08 & 0.359 & 0.723 & 0.170 & 0.865 \\
\hline & D20 & $\begin{array}{l}\text { Incompatible organizational cultures in the } \\
\text { contracting parties }\end{array}$ & 3.13 & 0.926 & 0.359 & 2.69 & -1.355 & 0.188 & 1.696 & 0.094 \\
\hline \multirow{2}{*}{$\begin{array}{l}\text { Cost and time to } \\
\text { conduct RC }\end{array}$} & D21 & High cost to adopt relational approaches & 3.00 & 0.000 & 1.000 & 2.69 & -1.316 & 0.200 & 1.178 & 0.246 \\
\hline & D22 & Time required to develop relationship & 3.31 & 2.311 & 0.025 & 3.00 & 0.000 & 1.000 & 1.182 & 0.241 \\
\hline \multirow[t]{7}{*}{$\begin{array}{l}\text { Uniqueness of } \\
\text { public projects }\end{array}$} & D18 & $\begin{array}{l}\text { Conservative industry culture inhibits changes and } \\
\text { encourages preservation of the status quo }\end{array}$ & 3.29 & 2.525 & 0.015 & 3.08 & 0.348 & 0.731 & 0.958 & 0.341 \\
\hline & D2 & Public sector accountability concems & 3.24 & 1.723 & 0.091 & 3.42 & 2.101 & 0.046 & -0.744 & 0.459 \\
\hline & D12 & Bureaucratic public client organization & 3.24 & 1.693 & 0.096 & 2.96 & -0.171 & 0.866 & 1.084 & 0.282 \\
\hline & D14 & Stringent public rules, regulations and laws & 2.77 & -1.947 & 0.057 & 3.08 & 0.328 & 0.746 & -1.300 & 0.197 \\
\hline & D17 & $\begin{array}{l}\text { Need to avoid possible allegations of corruption } \\
\text { arising from close relationships between client } \\
\text { and other contracting parties }\end{array}$ & 2.83 & -1.243 & 0.220 & 2.85 & -0.582 & 0.566 & 0.071 & 0.944 \\
\hline & D7 & Misgiving about potential future relationships & 3.30 & 2.260 & 0.028 & 2.77 & -1.063 & 0.298 & 2.185 & 0.032 \\
\hline & D23 & Client only has occasional need for project development & 2.80 & -1.347 & 0.184 & 2.88 & -0.486 & 0.631 & -0.305 & 0.762 \\
\hline
\end{tabular}

Note: $\mathrm{p}<0.05$ are shown in bold.

The lack of training and guidance in relational arrangement (D3) and lack of client's initiative in implementing RC practices (D11) significantly deter contracting parties in Beijing from adopting RC practices, but not in Sydney (see Table 4). This may be because relational contract is relatively new in China (Ke et al., 2013), while it is well established in Australia. The Chinese may be unable to see a 'win-win' scenario when adopting RC (Yeung et al., 2012), hence the lack of enthusiasm and initiative. For contracting parties in China to be better equipped with RC related knowledge, it is suggested that information relating to research findings and benchmarking studies be distributed and benefits of RC be promoted to them.

It is recommended that the Chinese government, which forms the top management, provides leadership to implement RC. This is because top management plays a vital role in developing and maintaining relationships (Rowlinson and Cheung, 2005).

The lack of empowerment in clients' representatives (D8) and the conservative industry culture that preserves the status quo (D18) significantly deter contracting parties in Beijing from adopting RC but not in Sydney (see Table 4). Chinese public clients may behave in this manner because they are infrequent or "one-off" clients and therefore lack interest in sustaining long-term relationships due to their short-term focus (Ke et al., 2011). Furthermore, clients are unwilling to empower their representatives because of their reluctance to break away from their traditional hierarchical position of control in their organizations. Australians on the other hand adopt an egalitarian attitude (Liang and Whiteley, 2003) rather than follow the hierarchical system like the Chinese. Thus Australian public clients can more easily empowered their representatives to make decisions. 
It is not easy for public clients in China to change their mindset about distribution of power due to the high power distance, where the society accepts the hierarchical order and people do not strive to equalize the distribution of power (Hofstede, 2012). It is suggested that public clients employ highly competent professionals to be their representatives. This way, they could trust the representative to execute their duties competently and in time, may be able to empower them.

The Chinese are significantly more deterred to adopt RC practices than Australians due to misgiving about potential future relationships (D7). In a market populated by a large number of $\mathrm{A} / \mathrm{E} / \mathrm{C}$ firms, Beijing respondents may have felt that there is only a slim chance to work together again in future projects which are procured through open tenders. Hence, there is a low potential to have future relationships with the same contracting parties in the current project. On the other hand, Australia's procurement system has developed beyond open tenders, and has other arrangements like alliance contracts (Rowlinson and Cheung, 2005) and serial contracts. These procurement methods allow current relationships in one project to be extended to the next, making future collaborations highly possible. It is suggested that the Chinese government consider alliance and serial contracting so that good performing A/E/C firms could be provided with longer runs of work, and longer term relationships can be nurtured. The use of cooperative procurement procedures should be considered as they give rise to better project performance (Eriksson and Westerberg, 2011).

Beijing respondents are significantly deterred from adopting RC because of the extra time required to develop relationships (D22). Indeed in China, developing relationships through guanxi is time consuming because it involves giving favors by offering short and long term rewards (Westwood and Chua, 1992) and maintaining and nourishing the guanxi over time (Yeung and Tung, 1996).

Moreover, short term goals may have caused contracting parties to feel that the time required to develop relationships is not worthwhile, especially when the potential for future relationships is low, given that new public projects are subjected to open competition.

Among the 23 possible barriers, Australian respondents indicated only 1 that is a significant barrier to adopting RC — public sector accountability concerns (D2). Transparency International (2012) ranked Australia and China's corruption perception at 8 (score 8.8) and 75 (score 3.6) respectively, where a country that is ranked first is the least corrupt country and a score of 0 means that a country is perceived as highly corrupted and 10 means very clean. The vast difference in perception of corruption may explain why public sector accountability is upheld as an important tenet in Australia. It is suggested that open markets that are not rife with corruption adopt certain RC practices that would not compromise public sector's accountability such as sharing of project information, aligning objectives of different parties, coordinating and monitoring plans jointly and sharing risks equitably.

\section{Conclusions}

RC is more efficient and effective than strict legal compliance because its cooperative approaches are based on the recognition of mutual benefits and win-win scenarios. The aim of this study is to conduct a comparative study of drivers and barriers to adopting RC practices in public construction projects in a centrally planned economy and an open market economy, represented by Beijing and Sydney respectively. A structured questionnaire was used to collect data from contracting parties who had been previously involved in public construction projects in these cities. Relationship quality among contracting parties was first analyzed to determine the nature of relationships among contracting parties in both cities. Further statistical tests were conducted to identify significant differences in drivers of and barriers to adopting RC between Beijing and Sydney. 
The results show that contracting parties' relationships at the inter-personal level, and at the end of the projects in both cities are all significantly good (see Table 2). It is acknowledged that respondents may be biased and provided positive views of the projects that they were involved in. On the other hand, the relationships may be truly good because RC practices were implemented. It was found that the inter-personal relations between contractors and consultants in Sydney are significantly better than in Beijing. This may be due to Beijing's large construction market having many $\mathrm{A} / \mathrm{E} / \mathrm{C}$ firms, making it more difficult for contractors and consultants to have such close relationships as in Sydney.

This study found many significant factors that drive the adoption of RC in both Beijing and Sydney (see Table 3). The results contribute to knowledge by showing that it is feasible to adopt RC practices in public construction projects in an open market economy (represented by Sydney), even though these projects are usually subject to a plethora of rules, regulations and institutional constraints. Similarly, in a planned economy, contracting parties can leverage on the many drivers identified in this study to adopt RC practices.

It was found that Beijing experiences 6 significant barriers while Sydney only has 1 significant barrier to adopting RC practices (see Table 4). This research further contributes to knowledge by showing that a centrally planned economy faces many barriers to adopting RC practices. The barriers are consistent with the government adopting a tight control and playing a big part in directing and controlling construction enterprises, causing public officials to lack initiative and empowerment, and preferring the status quo. The implication of the findings is that open market economies with low corruption are suitable to adopt RC, which requires frank and open communication and a collaborative project environment. On the other hand, a centrally planned economy may face some barriers in the adoption of RC practices.

The findings contribute to practice by identifying the drivers that are critical for cultivating readiness in embracing RC and the impeding factors that need to be overcome before RC practices can be implemented smoothly in two different markets.

It is recommended that the Chinese government makes use of its influential and controller position to encourage wider adoption of RC by introducing public policies and providing more opportunities for firms to work collaboratively. It is suggested that contracting parties in both market structures draw lessons from organizations that have successfully implement RC practices. It is further recommended that Chinese public clients appoint highly competent representatives to manage their projects so that they can be empowered to make right decisions. Instead of only open tenders, China could learn from Australia by adopting alliance and serial contracting so as to extend relationships across projects. Finally, while it is important to spend time to form and nurture relationships, Chinese contracting parties should not over do it because relationships have limitations. For example, it cannot be transferred from organization to organization, but reside within individuals.

This study has several limitations. It is acknowledged that the response rate in Sydney was low, despite many efforts made to raise it. The research compared two groups of public projects, one in Beijing and the other in Sydney, but in reality, it compared the perception of the professionals regarding the barriers and drivers that the projects faced in implementing RC practices. Nevertheless, the findings should not be negated by this as many other construction management research (e.g. Black et al., 2000; Chow et al., 2012; Li et al., 2001) was also based on perception of experts.

The next limitation is that data were only collected from Beijing and Sydney, which may not be representative of China and Australia respectively. Hence, the findings need to be generalized with 
care to the whole of China and Australia. Data were not collected from all across each country because the wide geographical spread may mean only a few set of project data could be collected from different cities. This may introduce further inaccuracy and bias.

The findings from Beijing and Sydney may be generalized to a limited extent, to other regions that operate as a centrally planned economy and an open market economy respectively. It should be kept in mind that countries are influenced by their national cultures, just as these findings are influenced by distinctive cultures in China and Australia. Also, results may not be representative of China and Australia as a whole. For future works, research may be extended to the whole of China and Australia, especially in regions that have significant construction activities and also to other countries with centrally planned economy and open market economy. A more concrete comparison can then be made between countries that operate under these 2 economic systems. Future studies could adopt indepth case study approach to corroborate the findings and validate the statistical results.

\section{Acknowledgments}

The research is made possible by Singapore Ministry of Education's Academic Research Fund Tier 2 funding support (grant number: MOE2009-T2-2-067) for the project entitled 'Boosting public construction project outcomes through relational transactions'.

\section{References}

Akintoye, A., Main, J., 2007. Collaborative relationships in construction: the UK contractors' perception. Engineering Construction and Architectural Management 14 (6), 597-617.

Akintoye, A., McIntosh, G., Fitzgerald, E., 2000. A survey of supply chain collaboration and management in the UK construction industry. European Journal of Purchasing and Supply Management 6 (3/4), 159-168.

Ali, A.-S., Mohd-Don, Z., Alias, A., Kamaruzzaman, S.-N., Pitt, M., 2010. The performance of construction partnering projects in Malaysia. International Journal of Physical Sciences 5 (4), 327-333.

Armstrong, G.D., 1980. Parametric statistics and ordinal data: a pervasive misconception. Nursing Research 30 (1), 60-62.

Australian Bureau of Statistics, 2012. Year Book Australia. http://www.abs.gov.au/ausstats/abs@.nsf/Lookup/by\%20Subject/1301.0 2012 Main\%20Fea tures Construction 32.

Bennett, J., Jayes, S., 1998. The Seven Pillars of Partnering: A Guide to Second Generation Partnering. Thomas Telford, London.

Black, C., Akintoye, A., Fitzgerald, E., 2000. An analysis of success factors and benefits of partnering in construction. International Journal of Project Management 18 (6), 423-434.

Bollen, R.A., 2007. Market failure and financial services - a case study of bounded rationality in the market for superannuation products. Macquarie Journal of Business Law 4, 49-70.

Bresnen, M., Marshall, N., 2000. Introduction to project alliancing: on engineering and construction projects. International Journal of Project Management 18 (2), 229-237.

Carifio, J., Perla, R., 2008. Resolving the 50-year debate around using and misusing Likert scales. Medical Education 42 (12), 1150-1152.

Chan, A., Chan, D., Ho, K., 2003. An empirical study of the benefits of construction partnering in Hong Kong. Construction Management and Economics 21 (5), 523-533.

Chow, P.T., Cheung, S.O., Chan, K.Y., 2012. Trust-building in construction contracting: mechanism and expectation. International Journal of Project Management 30 (8), 927-937. 
Colledge, B., 2005. Relational contracting — creating value beyond the project. Lean Construction Journal 2 (1), 30-45.

Construction Industry Institute (CII), 1991. In search of partnering excellence. Publication No. 17-1, Report CII, Austin, Texas.

Cook, E., Hancher, D., 1990. Partnering: contracting for the future. Journal of Management in Engineering 6 (4), 431-446.

Dong, G.T., 2009. Study on the developmental crisis of our country's consulting industry in China and corresponding countermeasures. Journal of Sci/Tech Information Development and Economy 19 (10), 77-78.

Drexler, J., Larson, E., 2000. Partnering: why project owner-contractor relationships change. Journal of Construction Engineering and Management, ASCE 126 (4), 293-297.

Egan, J., 1998. Rethinking construction. Report of the Construction Task Force on the Scope for Improving the Quality and Efficiency of UK Construction. Department of the Environment, Transport and the Regions, London.

Eriksson, P.E., Westerberg, M., 2011. Effects of cooperative procurement procedures on construction project performance: a conceptual framework. International Journal of Project Management 29 (2), 197-208.

Eriksson, P., Nilsson, T., Atkin, B., 2008. Client perceptions of barriers to partnering. Engineering Construction and Architectural Management 15 (6), 527-539.

Eriksson, E., Atkin, B., Nilsson, T., 2009. Overcoming barriers to partnering through cooperative procurement procedures. Engineering Construction and Architectural Management 16 (6), 598-611.

Gellerstam, M., Wiesner, J., 2010. The Impact of Guānxì in Chinese Business-A Study of Swedish SMEs in Beijing. University of Gothenburg, Gothenburg.

Glagola, C., Sheedy, W., 2002. Partnering on defense contracts. Journal of Construction Engineering and Management 128 (2), 127-138.

Hampson, K.D., Brandon, P., 2004. Construction 2020 - A Vision for Australia's Property and Construction Industry. CRC Construction Innovation, Brisbane.

Hofstede, G., 2012. National Culture Dimensions. http://geert-hofstede.com/dimensions.html.

Humphreys, P., Matthews, F., Kumaraswamy, M., 2003. Pre-construction project partnering: from adversarial to collaborative relationships. Supply Chain Management: An International Journal 8 (2), 166-178.

Jefferies, M., Brewer, G., Rowlinson, S., Cheung, Y.K., Satchell, A., 2006. Project Alliances in the Australian Construction Industry: A Case Study of a Water Treatment Project. Sustainability and Value through Construction Procurement. University of Salford.

Ke, Y., Ling, F., Kumaraswamy, M., Wang, S., Zou, P., Ning, Y., 2011. Are relational contracting principles applicable to public construction projects? Proceedings of RICS COBRA 2011, pp. 1364-1374 (Sep 12-13, 2011).

Ke, Y., Ling, Y.Y., Ning, Y., 2013. Public construction project delivery in Singapore, Beijing, Hong Kong and Sydney. Journal of Financial Management of Property and Construction 18 (1), 625.

Kumaraswamy, M., Ling, F., Rahman, M., Phg, S., 2005. Constructing relationally integrated teams. Journal of Construction Engineering and Management 131 (10), 1076-1086.

Kumaraswamy, M., Anvuur, A., Smyth, H., 2010. Pursuing “relational integration” and "overall value" through "RIVANS". Facilities 28 (13/14), 673-686.

Li, H., Cheng, E., Love, P., Irani, Z., 2001. An analysis of success factors and benefits of partnering in construction. International Journal of Project Management 19 (3), 171-179.

Liang, S., Whiteley, A., 2003. Australian businesses in China: searching for synergy. Asia Pacific Business Review 9 (3), 41-60. 
Ling, Y.Y., Tran, P.Q., 2012. Effects of interpersonal relations on public sector construction contracts in Vietnam. Construction Management and Economics 30 (12), 1087-1101.

Liu, J.Y., Low, S.P., 2007. Enhancing buildability in China's construction industry using Singapore's buildable design appraisal system. Journal of Technology Management in China 2 (3), 264278.

Liu, Y.W., Zhao, G.F., Wang, S.Q., 2010. Many hands, much politics, multiple risks — the case of the 2008 Beijing Olympics stadium. The Australian Journal of Public Administration 69 (S1), 85-98.

Lu, S., Yan, H., 2007. An empirical study on incentives of strategic partnering in China: views from construction companies. International Journal of Project Management 25 (3), 241-249.

Lu, W., Shen, L., Yam, a.M., 2008. Critical success factors for competitiveness of contractors: China study. Journal of Construction Engineering and Management 134 (12), 972-982.

Lummus, R.R., Vokurka, R.J., Alber, K.L., 1998. Strategic supply chain planning. Production and Inventory Management Journal 39, 49-58.

Luo, Y., 2007. Guanxi and Business. World Scientific Publishing, Singapore.

Macaulay, S., 1963. Non-contractual relations in business: a preliminary study. American Sociological Review 28 (1), 55-67.

Macneil, I., 1974. The many futures of contracts. South California Law Review 47 (3), 691-816.

Martinsuo, M., Ahola, T., 2010. Supplier integration in complex delivery projects: comparison between different buyer-supplier relationships. International Journal of Project Management 28 (2), 107-116.

McGregor, J., 2012. No Ancient Wisdom, No Followers: The Challenges of Chinese Authoritarian Capitalism. Prospecta Press, Westport, CT.

National Bureau of Statistics China, 2012. China Statistical Yearbook 2012. http://www.stats.gov.cn/tjsj/ndsj/2012/indexeh.htm.

Ng, S., Rose, T., Mak, M., Eng, S., 2002. Problematic issues associated with project partnering-the contractor perspective. International Journal of Project Management 20 (6), 437-449.

Nitschke, A., 2010. Australian Bureau of Statistics-A Statistical Overview of the Construction Industry. http://www.abs.gov.au/AUSSTATS/abs@.nsf/Lookup/1350.0Feature+Article1Oct+2010.

Norman, G., 2011. Likert scales, levels of measurement and the "laws" of statistics. Advances in Health Sciences Education 15 (5), 625-632.

Nunnally, J., 1978. Psychometric Theory. McGraw-Hill, New York.

Ott, R., Longnecker, M., 2001. An Introduction to Statistical Methods and Data Analysis. Pacific Grove, Duxbury.

Packham, G., Thomas, B., Miller, C., 2003. Partnering in the house building sector: a subcontractor's view. International Journal of Project Management 21 (5), 327-332.

Palaneeswaran, E., Kumaraswamy, M., 2000. Benchmarking contractor selection practices in publicsector construction-a proposed model. Engineering Construction and Architectural Management 7 (3), 285-299.

Palaneeswaran, E., Kumaraswamy, M., Ng, T., 2003. Targeting optimum value in public sector projects through "best value"-focused contractor selection. Engineering Construction and Architectural Management 10 (6), 418-431.

Rahman, M., Kumaraswamy, M., 2004. Contracting relationship trends and transitions. Journal of Management in Engineering 20 (4), 147-161.

Rahman, M., Kumaraswamy, M., 2005. Relational selection for collaborative working arrangements. Journal of Construction Engineering and Management 131 (10), 1087-1098.

Rahman, M., Kumaraswamy, M., 2008. Relational contracting and teambuilding: assessing potential contractual and non-contractual incentives. Journal of Management in Engineering 24 (1), 48-63. 
Ross, J., 2003. Introduction to project alliancing in engineering and construction projects. Proceedings of the Alliance Contracting Conference. Project Control International Pty Ltd., Sydney, pp. 1-42.

Rowlinson, S., Cheung, Y.K., 2005. Success factors in an alliance contract: a case study in Australia. Proceedings of the International Conference of AUBEA/COBRA/CIB Student Chapter, 4-8 July 2005. Queensland University of Technology, Brisbane, Queensland.

Sanders, S.R., Moore, M.M., 1992. Perceptions on partnering in the public sector. Project Management Journal 22 (4), 13-19.

Smyth, H., Edkins, A., 2007. Relationship management in the management of PFI/PPP projects in the UK. International Journal of Project Management 25 (3), 232-240.

Swan, W., Khalfan, M., 2007. Mutual objective setting for partnering projects in the public sector. Engineering Construction and Architectural Management 14 (2), 119-130.

Tai, S., Wang, Y., Anumba, C., 2009. A survey on communications in large-scale construction projects in China. Engineering Construction and Architectural Management 16 (2), 136-149.

Transparency International, 2012. Corruption Perceptions Index. http://cpi.transparency.org/cpi2011/results/.

Walker, D.H., Hampson, K., Peters, R., 2002. Project alliancing vs project partnering: a case study of the Australian National Museum Project. Supply Chain Management: An International Journal 7 (2), 83-91.

Wang, S.Q., Tiong, R.L., Ting, S.K., Ashley, D., 2000. Evaluation and management of political risks in China's BOT projects. Journal of Construction Engineering and Management, ASCE 126 (3), 242-250.

Westwood, R.I., Chua, B.L., 1992. Power, politics, and influence. In: Westwood, R.I. (Ed.), Organizational Behavior Southeast Asian Perspective. Longman, Hong Kong, pp. 144-172.

Williamson, O., 1975. Markets and Hierarchies: Analysis and Antitrust Implications. Free Press, New York.

Winn, P.R., Johnson, R.H., 1978. Business Statistics. Macmillan, New York.

Winter, J.C.F., Dodou, D., 2010. Five-point Likert items: t test versus Mann-Whitney-Wilcoxon. Practical Assessment Research and Evaluation 15 (11), 1-12.

World Economic Forum, 2012. The Global Competitiveness Report 2012-2013. WEF, Geneva.

Yeung, I.Y.M., Tung, R.L., 1996. Achieving business success in Confucian society: the importance of guanxi (connections). Organizational Dynamics 25 (2), 54-65.

Yeung, J.F., Chan, A.P., Chan, D.W., 2012. Defining relational contracting from the Wittgenstein family-resemblance philosophy. International Journal of Project Management 30 (2), 225239.

Zhang, S., 2003. Construction industry and enterprises in China: a comprehensive review. Proceedings of the CIB TG 23 International Conference, Hong Kong, China, pp. 1-12.

Zumbo, B.D., Zimmerman, D.W., 1993. Is the selection of statistical methods governed by level of measurement? Canadian Psychology 34 (4), 390-400. 